\title{
Methylxanthines (caffeine, pentoxifylline and theophylline) decrease the mutagenic effect of daunomycin, doxorubicin and mitoxantrone
}

\author{
Jacek Piosik ${ }^{1 \bowtie}$, Anna Gwizdek-Wiśniewska², Katarzyna Ulanowska³ ${ }^{3}$ Jakub \\ Ochociński ${ }^{1}$, Agata Czyż ${ }^{4}$ and Grzegorz Węgrzyn ${ }^{3,5}$ \\ ${ }^{1}$ Intercollegiate Faculty of Biotechnology, University of Gdańsk and Medical University of Gdańsk, Gdańsk, \\ Poland; ${ }^{2}$ Department of Pharmaceutical Technology and Biochemistry, Technical University of Gdańsk, Gdańsk, \\ Poland; ${ }^{3}$ Department of Molecular Biology, University of Gdańsk, Gdansk, Poland; ${ }^{4}$ Laboratory of Molecular \\ Biology (affiliated with the University of Gdańsk), Institute of Biochemistry and Biophysics, Polish Academy of \\ Sciences, Gdańsk, Poland; ${ }^{5}$ Institute of Oceanology, Polish Academy of Sciences, Gdynia, Poland;

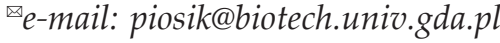

Received: 15 February, 2005; revised: 08 June, 2005; accepted: 24 June, 2005 available on-line: 11 July, 2005

\begin{abstract}
Previously performed experiments showed that methylxanthines, especially caffeine, may protect cells against cytostatic or cytotoxic effects of several aromatic compounds. One of the proposed mechanisms of this protection is based on stacking interactions between $\pi$ electron systems of polycyclic aromatic molecules. In this work, we demonstrate that caffeine and other methylxanthines - pentoxifylline and theophylline - significantly decrease mutagenicity of the anticancer aromatic drugs daunomycin, doxorubicin and mitoxantrone. The spectrophotometric titration of these aromatic compounds by methylxanthines indicated formation of mixed aggregates. The concentrations of free active forms of the drugs decreased when the concentrations of methylxanthines increased in the mixture. Therefore, likely methylxanthines may play a role of scavengers of the free active forms of daunomycin, doxorubicin and mitoxantrone.
\end{abstract}

Keywords: xanthines, daunomycin, doxorubicin, mitoxantrone, Vibrio harveyi mutagenicity assay

Methylxanthines (MTX), including caffeine (CAF), pentoxifylline (PTX) and theophylline (TH) are compounds commonly used worldwide. They are components of human diet as well as of several drugs (Marks \& Kelly, 1973; Medvei et al., 1974; Graham, 1978; Williams et al., 1978; Samlaska \& Winfield, 1994; Tanaka et al., 1991).

There are many known biological effects of MTX's action manifested, among others, by increased cytotoxicity or cytostaticity of various compounds, mainly by potentiating the activity of several DNA damaging agents (Donovan \& Dipaolo, 1974; Beetham et al., 1983; Fingert et al., 1984; 1986; Labanowska et al., 1988; Mourelatos et al., 1988; Tomita \& Tsuchiya, 1989; Boike et al., 1990; Petru et al., 1990; Tanaka et al., 1991; Fan et al., 1995; Ohsaki et al., 1996). On the other hand, it is well known that MTX also diminish the pharmacological action of aromatic drugs such as ellipticine, doxorubicin (DOX) and mitoxantrone (MIT) (Traganos et al., 1991a; 1991b), which are topoisomerase II blockers, as well as topotecan and camptothecin (Nahon et al., 1993) - topoisomerase I blockers. This protective action is not only specific for aromatic anticancer drugs but also for other aromatic chemicals of mutagenic activity, e.g. polycyclic aromatic hydrocarbons (PAHs) (Rothwell, 1974) and acridine mutagens (ICR 170, ICR 191) (Piosik et al., 2003).

These opposite effects can be explained in the following way. When DNA has already been damaged, the presence of MTX causes a diminution of DNA repair or synthesis (Roberts, 1984; Roberts \& Kotsaki Kovatsi, 1986; Selby \& Sancar 1990). Therefore, the presence of MTX enhances DNA damages. However, if MTX are available before aromatic drug administration or are administrated together with aromatic drugs, a protective effect is observed. It was proposed previously that this protective effect of MTX is a result of direct stacking interactions between MTX and aromatic molecules (Traganos et al., 1991b; 1993; Kapuscinski \& Kimmel, 1993; Zdunek et al., 2000; Kapuscinski et al., 2002; Piosik 
et al., 2002; 2003). These interactions are very weak (mixed association constant $K_{A C}$ about $10^{2} \mathrm{M}^{-1}$ ) and can be disrupted easily. It seems plausible that this phenomenon may be used to diminish some side effects associated with the high local concentrations of anticancer drugs in the initial phase of their administration (Hande, 1998). Formation of complexes between MTX and aromatic drugs may lead to temporal reduction of the concentration of free drug molecules available for the cells. In this work we investigated the mutagenic activity of chosen aromatic anticancer drugs and the possible modulation of their mutagenic activity by methylxanthines - caffeine, pentoxifylline and theophylline.

\section{MATERIALS AND METHODS}

Chemicals. All chemicals used in this work: caffeine (1,2,3-trimethylxanthine, CAF), pentoxifylline (3,7-dimethyl-1-(5-oxohexyl)xanthine, PTX, trental), theophylline (1,3-dimethylxanthine, $\mathrm{TH})$, daunomycin ((8S-cis)-8-acetyl-10-[(3-amino-2,3,6-trideoxy- $\alpha$-L-lyxo-hexopyranosyl)oxy]-7,8,9,10-tetrahydro6,8,11-trihydroxy-1-methoxy-5,12-naphthacenedione, DAU), doxorubicin (14-hydroxydaunomycin, DOX), and mitoxantrone (1,4-dihydroxy-5,8-bis[[2-[(2-hydr oxyethyl)amino]ethyl]amino]-9,10-anthracenedi-one, MIT) were purchased from Sigma-Aldrich. Their chemical structures are presented in Fig. 1.

The Vibrio harveyi mutagenicity assay. The assay was performed in liquid medium as described previously (Czyz et al., 2000; 2002). Briefly, Vibrio harveyi BB7 strain was cultivated in BOSS medium (Klein et al., 1995) at $30^{\circ} \mathrm{C}$. To exponentially growing cultures, indicated components were added and cultivation was continued for $3 \mathrm{~h}$. On the basis of preliminary experiments, the following drug concentrations were chosen to induce mutagenic but not cytostatic or cytotoxic effects: $0.4 \mu \mathrm{M}$ DAU, $0.03 \mu \mathrm{M}$ DOX, $0.6 \mu \mathrm{M}$ MIT (under these drug concentrations significant mutagenic effects were observed, see Fig. 2, but no significant decrease in bacterial growth rate and survival was detected). The methylxanthines were added together with the drugs, at a final concentration of $1 \mathrm{mM}$. After cultivation in the liquid medium, $5 \cdot 10^{6}$ cells were spread onto BOSS agar plates containing neomycin $(0.1 \mathrm{mg} / \mathrm{ml})$. Following a $48 \mathrm{~h}$ incubation at $30^{\circ} \mathrm{C}$, neomycin-resistant colonies were counted.

To estimate the number of spontaneous neomycin-resistant mutants, analogous experiments were performed in which neither methylxanthines nor drugs were added. The number of such mutants (which was between 10 and 20 in all experiments) was then subtracted from the number of mutants in cultures treated with methylxanthines and/or drugs.

Light absorption spectrometry. Light absorption spectra were measured using a Beckman DU 650 spectrophotometer connected with a Polystat thermostat constant circulator $\left(25 \pm 0.1^{\circ} \mathrm{C}\right)$. Two milliliters of a buffer ( $5 \mathrm{mM}$ Hepes, $150 \mathrm{mM} \mathrm{NaCl}$, pH 7.1) containing DAU, DOX or MIT were placed in a quartz cuvette $(1 \mathrm{~cm}$ light path) and titrated with $5-150 \mu \mathrm{L}$ of CAF, PTX (concentration $0.1 \mathrm{M}$ ) or TH (concentration $0.02 \mathrm{M}$ ) dissolved in the buffer. The spectra were measured at $0.5 \mathrm{~nm}$ intervals and stored on a computer disk. The spectra were then corrected for the absorption of the buffer, CAF, PTX and TH, and expressed in terms of the molar absorption coefficient $\left(\varepsilon_{\lambda^{\prime}} \mathrm{M}^{-1} \cdot \mathrm{cm}^{-1}\right)$.

Calculation of association constants. Calculations of the association constants of DAU, DOX or MIT with CAF, PTX and TH were accomplished using statistical thermodynamics of mixed aggregation (Kapuscinski \& Kimmel, 1993; Zdunek et al., 2000; Kapuscinski et al., 2002; Piosik et al., 2002; 2003). The notations and definitions described previously by Weller and co-workers (1984) were employed.

\section{RESULTS AND DISCUSSION}

Using a previously developed mutagenicity assay (Czyz et al., 2000; 2002), we investigated the effects of methylxanthines (CAF, PTX, TH) on the mutagenic activity of three anticancer drugs DAU, DOX and MIT. In all cases a strong mutagenic effect of the analyzed drugs was observed (Fig. 2A). All methylxathines tested, CAF, PTX and TH, had

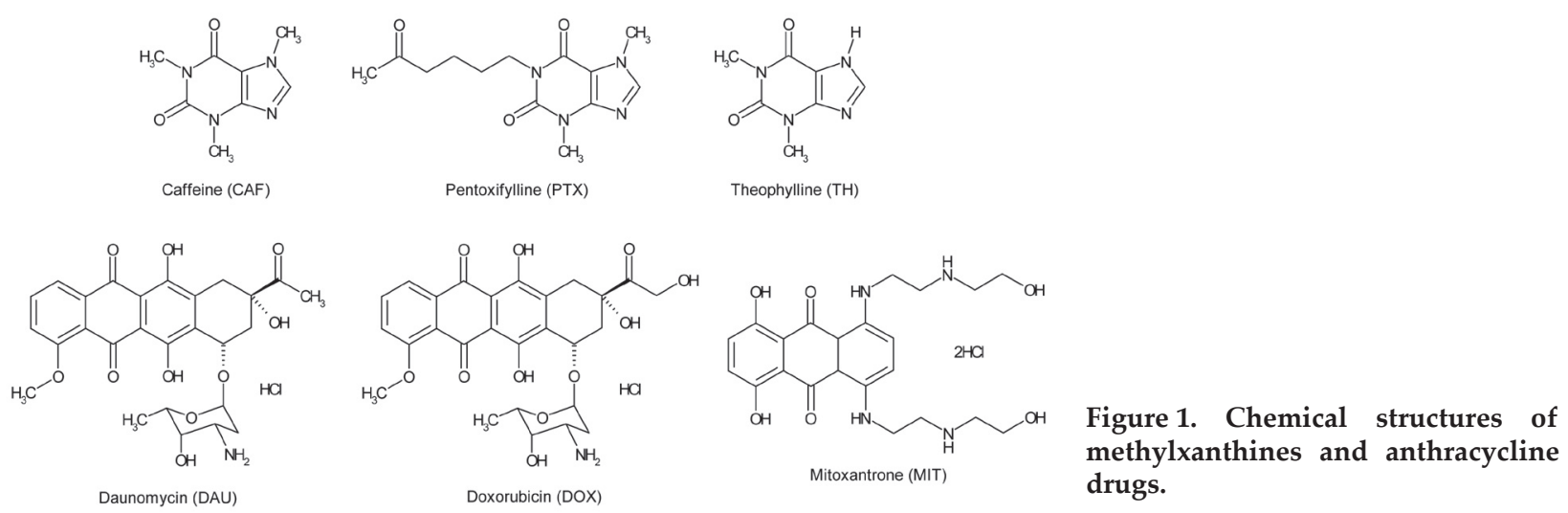


no significant mutagenic effect at the concentrations examined $(0.5-2.5 \mathrm{mM})$. We found that the mutagenicity of DAU, DOX and MIT was significantly decreased when they were administrated together with the methylxanthines (at a final concentration of $1 \mathrm{mM}$ ) (Fig. 2B, C, D). Similar effects were observed for MTX concentrations ranging from 0.5 to $2.5 \mathrm{mM}$ (not shown). Therefore, we conclude that methylxanthines alleviate the mutagenic effects of DAU, DOX and MIT.

At low concentrations the anticancer drugs DAU, DOX and MIT cause mutagenic effects in $\mathrm{Vi}$ brio harveyi cells. Higher concentrations were toxic to these bacteria (not shown). At the concentrations used here, administration of MTX alone exerts no mutagenic effects. It is necessary to underline that the examined aromatic drugs were added to the cells together with MTX in the mixture, and MTX concentrations were significantly higher than the drug concentrations. Nevertheless, in all cases, a considerable decrease in the mutagenicity of the examined aromatic drugs was observed in the presence of MTX (Fig. 2). Therefore, all MTX tested may scavenge the free forms of DAU, DOX and MTX. It is worth noting that this process is dynamic and reversible, and if the MTX concentration is lowered, free molecules of active drugs may re-appear.

Using light absorption spectroscopy we examined possible direct interactions between methylxanthines and DAU, DOX and MIT. It has been demonstrated that interactions between $\pi$ electron systems from aromatic rings of aggregating chemicals may occur (Traganos et al., 1991b; 1993; Kapuscinski \&

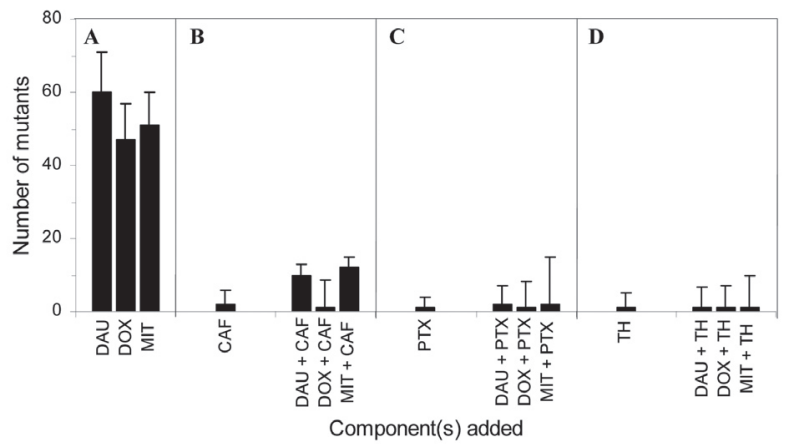

Figure 2. Effects of methylxanthines - caffeine (CAF), pentoxifylline (PTX) and theophylline $(\mathrm{TH})$ - on mutagenicity of chosen aromatic anticancer drugs: daunomycin (DAU), doxorubicin (DOX) and mitoxantrone (MIT). The mutagenicity test was performed as described in Materials and Methods. Effects of drugs added alone are presented in panel $\mathrm{A}$ and effects of methylxanthines added alone or together with drugs are presented in panels B (caffeine), C (pentoxifylline) and D (theophylline). The number of mutants is given after subtraction of the number of spontaneous mutants (10-20 per plate). Average values of three experiments are presented with error bars indicated.
Kimmel, 1993; Zdunek et al., 2000; Kapuscinski et al., 2002; Piosik et al., 2002; 2003).

Based on the data obtained by spectrophotometric titrations and using the thermodynamical model of mixed association (Kapuscinski \& Kimmel, 1993) we calculated all concentrations of neighborhoods and the "neighborhood associations" constants $K_{A C}$ for all systems (Table 1 ). These results show that CAF, as well as PTX and TH, directly interact with the aromatic drugs through formation of stacking complexes. This causes a decrease in the concentrations of the free active form of the drugs when the MTX concentration increases in the mixture (not shown). This is in accord with earlier results which focused on direct interactions between several aromatic compounds, like acridine orange (Kapuscinski \& Kimmel, 1993), ethidium bromide, DAPI (Zdunek et al., 2000), DOX, MIT (Piosik et al., 2002), quinacrine mustard with CAF (Kapuscinski et al., 2002), and quinacrine mustard, ICR-191, ICR170 (Piosik et al., 2003) with CAF or PTX. Johnson et al. (2003) also revealed that MTX, theophylline, theobromine and caffeine, can directly interact with intercalated dyes - ethidium bromide and acridine orange-effecting their de-intercalation from calf thymus DNA and reduction of DNA - directed toxicity.

All examined drugs cause serious side effects on intravenous or oral administration, e.g. extravasation and local tissue necrosis (Rudolph \& Larson, 1987; Richardson \& Johnson, 1997; Heitmann et al., 1998; Slattery et al., 1999; Kassner, 2000; Sparreboom et al., 2002) due to their high local concentrations. Several MTX, including CAF, PTX and TH, are also used as medicines (Graham, 1978; Samlaska \& Winfield, 1994; Shannon, 2004). One might speculate that the use of suitable combinations of aromatic anticancer drugs with MTX could contribute to a temporal decreases of the high local concentrations of the active forms of the drugs and thus limit their undesirable side effects. This would not necessarily mean a decrease in the activity of these drugs in the anticancer therapy. A decrease in MTX concentration due to its dilution in the blood would cause an increase in the amount of free drug that could react further on. To obtain such an effect, it would be necessary to match suitable proportions of MTX and the drug,

Table 1. Mixed association constants calculated for interactions between analyzed compounds

\begin{tabular}{llll}
\hline \multirow{2}{*}{$\begin{array}{l}\text { Methylxan- } \\
\text { thines }\end{array}$} & \multicolumn{3}{l}{$\begin{array}{l}\text { Mixed association constants with aromatic } \\
\text { drugs } K_{A C} \pm \text { S.E. }\left(\mathrm{M}^{-1}\right)\end{array}$} \\
\cline { 2 - 4 } & DAU & DOX & MIT \\
\hline CAF & $148.5 \pm 4$ & $128.3 \pm 10^{*}$ & $356.4 \pm 21^{*}$ \\
PTX & $172.7 \pm 5$ & $173.0 \pm 5$ & $218.2 \pm 7$ \\
TH & $99.9 \pm 5$ & $364.5 \pm 15$ & $222.7 \pm 9$ \\
\hline
\end{tabular}

*Data from other publication (Piosik et al., 2002) 
which could be determined on the basis of the calculated mixed association constant, $K_{A C}$. We speculate that in such a case it would be not necessary to use MTX at concentrations as high as those used in this work in the mutagenicity test (total concentrations of MTX between 0.5 and $2.5 \mathrm{mM}$ ). Based on the spectrophotometric data and the results calculated from the thermodynamical-statistical model of mixed aggregation in aqueous solutions we observed that formation of stacking complexes between MTX and an aromatic drug occurs at significantly lower concentrations of MTX. It was also demonstrated that at a relatively high concentration $(5 \mathrm{mM}) \mathrm{CAF}$ has no significant effect on cell growth or cell cycle progression and distribution (Traganos et al., 1991a; 1991b; 1993). On the other hand, there are published data indicating that CAF and PTX may be toxic at concentrations of $2.24-3.92 \mathrm{mM}$ and $3.17-6.0 \mathrm{mM}$, respectively, to several human cell lines (Bohm et al., 2000). This problem requires further detailed studies if one considers MTX as a potential auxiliary drug to be used in combination with DAU, DOX or MIT.

\section{Acknowledgements}

This work was supported by the University of Gdańsk (grant no. BW/B000-5-0218-1 and BW/B0525-0035-2 to J.P.) and by the Ministry of Science and Information Society Technologies (grant No. 2 P04G $01126)$.

\section{REFERENCES}

Beetham KL, Busse PM, Tolmach LJ (1983) J Cell Physiol 115: 283-290.

Bohm L, Theron T, Binder A (2000) Biochim Biophys Acta 1499: $1-10$.

Boike GM, Petru E, Sevin BU, Averette HE, Chou TC, Penalver M, Donato D, Schiano M, Hilsenbeck SG, Perras J (1990) Gynecol Oncol 38: 315-322.

Chaires JB, Dattagupta N, Crothers DM (1982) Biochemistry 21: 3927-3932.

Czyz A, Jasiecki J, Bogdan A, Szpilewska H, Wegrzyn G (2000) Appl Environ Microbiol 66: 599-605.

Czyz A, Szpilewska H, Dutkiewicz R, Kowalska W, Biniewska-Godlewska A, Wegrzyn G (2002) Mutat Res 519: 67-74.

Donovan PJ, Dipaolo JA (1974) Cancer Res 34: 2720-2727.

Fan S, Smith ML, Rivet DJ, Duba D, Zhan Q, Kohn KW, Fornace AJ Jr, O'Connor PM (1995) Cancer Res 55: 1649-1654.

Fingert HJ, Kindy RL, Pardee AB (1984) J Urol 132: 609_ 613.

Fingert HJ, Chang JD, Pardee AB (1986) Cancer Res 46: 2463-2467.

Graham DM (1978) Nutr Rev 36: 97-102.

Hande KR (1998) Biochim Biophys Acta 1400: 173-184.
Heitmann C, Durmus C, Ingianni G (1998) J Hand Surg (Br) 3: 666-668.

Johnson IM, Kumar SG, Malathi R (2003) I Biomol Struct Dyn 20: 677-686

Kapuscinski J, Kimmel M (1993) Biophys Chem 35: 46-53.

Kapuscinski J, Ardelt B, Piosik J, Zdunek M, Darzynkiewicz Z (2002) Biochem Pharmacol 63: 625-634.

Kassner E (2000) J Pediatr Oncol Nurs 17: 135-148.

Kharasch ED, Novak RF (1984) Arch Biochem Biophys 234: 497-512.

Klein G, Walczak R, Krasnowska E, Blaszczak A, Lipinska B (1995) Mol Microbiol 16: 801-811.

Labanowska J, Beetham KL, Tolmach LJ (1988) Radiat Res 115: $176-186$.

Marks V, Kelly JF (1973) Lancet 1: 827.

Medvei KK, Sved S, Hossie RD, Garratini S (1974) Biomed Mass Spectrom 4: 172-177.

Menozzi M, Valentini L, Vannini E, Arcamone F (1984) J Pharm Sci 73: 766-770.

Mourelatos D, Dozi Vassiliades J, Kotsis A, Gourtsas C (1988) Cancer Res 48: 1129-1131.

Nahon E, Best Belpomme M, Saucier JM (1993) Eur J Biochem 218: 95-102.

Ohsaki Y, Ishida S, Fujikane T, Kikuchi K (1996) Oncology 53: 327-333.

Petru E, Boike G, Sevin BU (1990) I Cancer Res Clin Oncol 116: 431-433.

Piosik J, Zdunek M, Kapuscinski J (2002) Biochem Pharmacol 63: 635-646.

Piosik J, Ulanowska K, Gwizdek-Wisniewska A, Czyz A, Kapuscinski J, Wegrzyn G (2003) Mutat Res 530: 47-57.

Richardson DS, Johnson SA (1997) Blood Rev 11: 201-223.

Roberts JJ (1984) In Mechanism of Potentiation by Caffeine of Genotoxic Damage Induced by Physical and Chemical Agents: Possible Relevance to Carcinogenesis. Dews PB, ed, pp 239-253. Springer-Verlag, Berlin, New York.

Roberts JJ, Kotsaki Kovatsi VP (1986) Mutat Res 165: 207220.

Rothwell K (1974) Nature 252: 69-70.

Rudolph R, Larson DL (1987) J Clin Oncol 5: 1116-1126.

Samlaska CP, Winfield EA (1994) J Am Acad Dermatol 30: 603-621.

Selby CP, Sancar A (1990) Proc Natl Acad Sci USA 87: 3522-3525.

Shannon M (2004) Clin Ped Emerg Med 1: 213-221.

Slattery ML, Caan BJ, Anderson KE, Potter JD (1999) Int J Cancer 81: 199-204.

Sparreboom A, de Jonge MJ, Verweij J (2002) Eur J Cancer 38: $18-22$

Tanaka J, Teicher BA, Herman TS, Holden SA, Dezube B, Frei E (1991) Int J Cancer 48: 631-637.

Tomita K, Tsuchiya H (1989) Jpn J Cancer Res 80: 83-88.

Traganos F, Kaminska Eddy B, Darzynkiewicz Z (1991a) Cell Prolif 24: 305-319.

Traganos F, Kapuscinski J, Darzynkiewicz Z (1991b) Cancer Res 51: 3682-3689.

Traganos F, Kapuscinski J, Gong J, Ardelt B, Darzynkiewicz RJ, Darzynkiewicz Z (1993) Cancer Res 53: 4613 -4618 .

Weller K, Schutz H, Petri I (1984) Biophys Chem 19: 289 298.

Williams JF, Lowitt S, Polson JB, Szentivany A (1978) Biochem Pharmacol 27: 1545-1550.

Zdunek M, Piosik J, Kapuscinski J (2000) Biophys Chem 84: $77-85$. 